\title{
The use of the Repertory Grid for collaboration and reflection in a research context
}

\author{
Patricia Alexander ${ }^{1}$, Johan van Loggerenberg ${ }^{2}$, Hugo Lotriet ${ }^{3}$, Jackie Phahlamohlaka ${ }^{4}$ \\ 1,2,3 Department of Informatics, University of Pretoria, Hatfield, PRETORIA, 0083, South \\ Africa \\ Patricia.Alexander@up.ac.za \\ 4 Department of Informatics, University of Pretoria and Council for Scientific and Industrial \\ Research (CSIR), Pretoria, South Africa \\ JPhahlamohlaka@csir.co.za \\ Running head: Repertory Grid for collaboration \& reflection
}

\section{ABSTRACT}

The Repertory Grid (RepGrid) technique has been used extensively in Management Sciences research, including Information Systems research, in order to reveal the personal views of individual research subjects regarding the issue being studied. These individual constructs are then used to propose criteria for success amongst other things. This paper uses a distinctly different form of RepGrid, renamed a Reflection Grid, as a collaboration tool. Members of a research team use this new technique to probe their individual understanding of what happened and what was achieved during a research event and then share these. Hence, not only is the application new (reflection and construction of shared meaning rather than the analysis and synthesis of personal constructs) but the original grid technique has evolved.

\section{KEY WORDS}

Repertory grid, personal constructs, Information Systems research methodology,

collaboration, qualitative research. 


\title{
The use of the Repertory Grid for collaboration and reflection in a research context
}

\author{
Patricia Alexander ${ }^{1}$, Johan van Loggerenberg ${ }^{2}$, Hugo Lotriet $^{3}$, Jackie Phahlamohlaka ${ }^{4}$ \\ 1,2,3 Department of Informatics, University of Pretoria \\ Patricia.Alexandereup.ac.za \\ 4 Department of Informatics, University of Pretoria and Council for Scientific and Industrial \\ Research (CSIR), Pretoria, South Africa \\ JPhahlamohlaka@csir.co.za
}

\section{Introduction}

IS researchers and other collaborators need to be able to share concepts and perceptions effectively within their research teams and to be able to identify occasions when, in fact, they are not succeeding in doing this. Construction of shared meaning is easier when a team trusts one another and have a shared vocabulary, a reasonably long period during which they have worked together and built up common experiences, and have had sufficient time in which to discuss the concepts and are co-located (Jarvenpaa and Leidner 1998; Finholt 2001; Alexander 2002; 2004). All of these assist in improving communication. However, these ideal conditions are not always possible and in those circumstances additional care needs to be taken to improve the chance that the message will be understood. The process can be improved by being reflective, and hence aware of one's own assumptions and biases, and making these explicit. Structured techniques, where both the development process and the clear expression of concepts are facilitated, form a significant part of work on collaboration and creativity (Briggs et al. 2003; De Bono 1992; Dix et al. 2006). Techniques of this kind remind the participants of necessary activities and social rules (such as turn taking, paying attention when others contribute to the discussion, and documenting ideas) which are often ignored in the heat of an unstructured discussion.

The techniques can, in turn, be incorporated into groupware. The goals stated in the quotation provided below clearly describe the objectives of Group Support Systems and their role in collaboration.

'There is a sense that groupware can radically affect the dynamics of team interactions

by improving communication, by structuring and focusing problem-solving efforts, and by establishing and maintaining a balance and alignment between personal and group goals.' (De Vreede, Mgaya and Quresh 2003)

This research study set out to identify how effective the Repertory Grid (RepGrid) technique was as a structured technique for use in collaboration within an interpretive research paradigm.

RepGrid is a method of collecting rich data during a structured, reflective process where the individual participants uncover their own 'personal constructs' or understanding of a given concept, attitude or perception. The participants largely work independently, with the researcher acting as facilitator only in terms of the process. The method thus allows for the elimination of observer ('researcher') bias (Stewart and Stewart 1990). Each participant enters information in a grid format as will be described below, and these sets of data are used as input to the analysis undertaken by the researcher. The method holds great potential as it assists the participants in deliberately identifying and explicitly stating their own understanding or perception of the issue being studied. It also provides the researcher with both qualitative and quantitative data which can be interpreted and analyzed. The 
interpretation of the qualitative data, as is the case with all such data, relies on the insight of the researcher and is, therefore, challenging. Statistical methods can be used to analyze the quantitative data obtained, but, as always, this must be done properly in order not to misrepresent the situation.

The use of RepGrid and its expansion into various fields ranging from managerial studies to evaluation of training and counselling and its adoption in both academia and industry demonstrate that the method is widely considered useful (Stewart and Stewart 1990).

The goal of the research reported here was to confirm that the RepGrid could be used as a collaborative technique and not only to identify and rank success factors. The proposition was that RepGrid could be used to assist team members in collaborating by making the individual concepts (personal constructs) explicit and hence allowing joint concepts to be formed.

As will be explained, the endeavour resulted in an extension of the RepGrid technique for use in Information Systems (IS) research, particularly in instances where collaborative reflection is required, for example during the evaluation phase of Action Research. In the case presented as an example in this paper the researchers themselves completed the RepGrids as part of an evaluative phase of an Action Research project and this allowed them an opportunity for critical assessment of their assumptions and the observations made during the research event and hence introspection. However, as will be seen, this extended use of the RepGrid is not limited to IS research but is appropriate in any context where common ground and shared meaning is sought. The paper not only proposes a new version intended for use for collaboration by a team of researchers involved in interpretive research, but also illustrates this by means of an example. We believe that this extended use of the RepGrid provides an important new research method, particularly where a structured way of reflection on a process is required.

The paper is structured as follows: The need for the current research is explained. The origins of the technique, more detail regarding its basic or 'classical' use and ways in which it has been used (particularly in Information Systems research) are described. In the next section the particular research study and the unconventional way in which RepGrid was used in that study, are explained. This use has been renamed Reflection Grid to distinguish it from the RepGrid. A comparison between this Reflection Grid and the original RepGrid is undertaken in a further section. A Conclusion is provided in which new insights are noted.

\section{The need for the current research}

The authors were using Action Research (AR) as an approach in a community Information systems project (see case study example in Section 4).

$\mathrm{AR}$ as a method for socio-technical research in Information Systems has become quite popular, with numerous examples of research using this method having been published during the course of the past number of years - notably Iversen et al. (2004), Lindgren et al. (2004), Mårtensson et al. (2004) and others. Its popularity relates to its suitability for the study of complex non-reducible systems and the opportunity for the researchers to not only study a complex phenomenon, but be involved in practical solutions to real-life problems (Baskerville and Pries-Heje, 1999).

AR typically has a cyclical nature, in which action and reflection alternate; one of the popular conceptualisations is the one by Susman and Evered (1978) in which the process is structured as cycles of diagnosis, planning of actions, acting, evaluation of actions and specification of the learning that has taken place.

As a result of its popularity various aspects of $A R$ as a method have been discussed by various researchers. Notable for the purposes of this research paper are those identified by Baskerville and Pries-Heje (1999), namely: (1) The rigour of AR is largely situated in the structuring of the processes followed and, therefore, these should be continuously improved to strengthen the rigour; (2) AR is collaborative. 
The authors as a research team are diverse, with different cultures, languages and qualifications. In the stage of the AR cycle where actions need to be evaluated and learning specified, they were confronted with the following challenges:

1) How does a team of researchers collaborate on the evaluation when each team member has his/her own conceptualisation of the way in which a particular 'event' or action should be evaluated?

2) How could such a collaborative process be made more structured and explicit in order to contribute to the eventual rigour of the research?

The authors turned to the work of Kelly on personal constructs in order to address this problem (Kelly, 1955). The development of the RefGrid described in this paper is based on his Repertory Grid and has as its purpose the structuring of scientific collaboration amongst individual research team members, specifically as required in the evaluation and specification of learning phases of AR projects. However, as stated in the Introduction, the authors believe that the RefGrid has wider applicability to other (non-AR) situations where a quantitative evaluation of complex events or actions is required.

\section{Literature on RepGrid}

\subsection{Description of the 'classic' RepGrid technique}

A RepGrid session involves a number of participants who are knowledgeable about the topic being explored and a researcher or facilitator. Figure 1 provides an overview of the process and depicts the role players, their input, and how the data is subsequently aggregated. As can be seen in this diagram, the participants usually construct their own RepGrids without consulting one another.

A RepGrid is a matrix consisting of columns, in which elements are listed, and rows for the constructs (Figure 2). The elements are specific, concrete examples that will be used to help the participants to identify their own constructs or perceptions regarding the particular research topic that is being considered. The steps in the process of compiling and analyzing data using a RepGrid are illustrated in Figure 3.

The first step is identifying a topic. Examples of topics used in the IS literature are: Identifying desirable characteristics of systems analysts (Hunter and Beck 2000) or information systems (Whyte and Blytheway 1996). Figure 2 shows a RepGrid that is typical of one prepared by a single participant. The topic is: Desirable characteristics of IS development methodologies. The elements $\mathrm{A}, \mathrm{B}, \mathrm{C}, \mathrm{D}$ and $\mathrm{E}$ represent specific IS methodologies. The element domains (Hunter and Beck refer to 'audience') are generally represented as nouns, (for example, IS methodologies) but could be verbs as well (Stewart and Stewart 1990). Stewart and Stewart (op. cit.) indicate three possible ways of eliciting elements; these are (1) the researcher prepares an element list; (2) each participant creates a list; (3) the participants are prompted by the researcher to help them create lists. All three methods have advantages and disadvantages.

In our example, the option of eliciting the elements from the participants (option 2) has been chosen. Hence, participants are asked to identify five or more specific IS methodologies that they know quite well and to assign letters or numbers to them (Figure 3, step 2). Each of these is an element and is written on a slip of paper. They should represent a spectrum of methodologies which are considered to be more or less successful and should include a best and worst element. Alternatively they should include an ideal and least desirable element even if no actual corresponding example exists. The elements' identifiers are written into the grid as column headings. (In Figure 2, the methodologies are identified as A, B, C, D and E.) Participants are likely to identify different elements, but all would be examples from the same domain. Hence, in Figure 2, all elements would represent IS methodologies. The elements should be precise, homogeneous in that they should all come from a single element domain, not explicitly evaluative (except in the case of artificially chosen best and worst examples), 
representative, meaningful and relevant to participants, and should vary quite extensively in that the different elements should be contrasting examples within the same domain (Tan and Hunter 2002).

In the process known as triading (Figure 3, step 3), the participants are asked to randomly select three of the slips of paper (hence selecting three elements). These are used to formulate a construct, that is, a brief description of a characteristic of the elements, such that two of the selected individuals are similar in some way and the third is relatively dissimilar. (In the example in Figure 2, the first construct indicates that two of the three IS methodologies have been discussed regularly in A list IS journals and the third is less well known.) The participant writes the construct as the row label in the matrix in the form of two contrasting or bipolar statements (Figure 3, step 4). The first, placed on the leftmost side of the row, highlights what the pair of selected elements has in common and the second, written on the right hand side, why the singleton is different. Since each participant works independently, the constructs will differ. It is important that pairs of contrasting statements are formulated explicitly, as the process of looking for similarities and contrasts is an important part of attaining real understanding (Marsden and Littler 2000).

The next activity (Figure 3, step 5) requires the participants, still working independently, to evaluate each element with respect to the construct and to fill in a score in the appropriate cell of the grid. A high score indicates that the element closely resembles the description on the right. Hence, a score of 1 means that the element matches the description in the left hand column very closely, while a score of 5 means that this element is the one closest to the contrasting description given in the right hand column. Intermediate values indicate elements that are judged as being somewhat between the extremes. More than one element may have the same score, but there should be at least one score of 1 and one 5 in each row. In Figure 2, A has a score of 5 for published evaluations of the methodology and this indicates that the participant who completed this RepGrid believes that little has been published about methodology A, whereas methodology C, whose score is 1, has been discussed frequently. (The actual range of scores depends on the number of elements and the researcher decides what this should be.) The process of triading, identifying constructs and scoring is repeated and continues for as long as the researcher or time allows. Hence, each of the participants makes explicit his or her own personal set of constructs and evaluates the elements that he or she identified in terms of these constructs. This process of reflection is recorded by each participant with very little interference by anyone else. This part of the process collects the research data.

To recap, in Figure 2 we can see that the particular person who created this RepGrid has identified five IS development methodologies, and given them pseudonyms A, B, C, D and E. He has decided that a good IS methodology should be discussed regularly in top (A list) IS journals and has identified the 'opposite' as being 'relatively unknown'. He then scored each of the elements according to this pair of constructs and in Figure 2 we can see that methodology A has been discussed in few publications (score of 5 indicates that it is closest to the construct on the right) while $\mathrm{C}$ has been discussed in many (is closest to the construct on the left). If we limit the analysis to this one RepGrid, but look at all the constructs and scores it appears that $\mathrm{C}$ is the IS methodology that is most successful. All the constructs support this. $\mathrm{E}$ appears to be the least successful methodology, and once again the constructs consistently support this conclusion. (If one construct contradicted the others it would indicated that that construct should not be used as a critical success factor.)

The researcher then starts a process of categorizing all the data from all the individual RepGrids by studying the constructs proposed by the various participants and identifying those that are basically the same or are at least quite similar (thus the personal constructs are combined to form 'grouped constructs' or attributes (Whyte and Blytheway 1996)) (this is shown in Figure 3, step 7). Since proponents of this technique usually emphasize rigor and objectivity, more than one person may be asked to carry out this process and the team of researchers will strive to achieve consensus.

Finally, the scores from the individual sheets are aggregated per grouped construct. Often RepGrid results are subjected to rigorous statistical treatment (Lee and Truex 2000; Bell et al. 
2002; Harter et al. 2004), especially when the research is focused on predictive and explanatory issues (Figure 3, step 8). Thus, scores may be analyzed statistically in order to find out which of the grouped constructs were most closely and consistently associated with the elements that the individual participants identified as being the best or worst examples from the research domain (for example, the best information systems development methodology). The statistical methods allow a ranking score to be calculated for each grouped construct by comparing it with an overall goal construct (here the overall value of various IS development methodologies), and this allows assessment of the perceived contribution of that grouped construct to the overall goal. Hence grouped constructs can be ranked in terms of whether they appear to be reliable predictors of success. Specific processing algorithms and computer programs such as FOCUS, GAP, PREFAN, SOCIOGRIDS MINUS CORE and ARGUS exist specifically for this purpose (Lee and Truex 2000; Marsden and Littler 2000) but (additional) manual analysis has the advantage of allowing more understanding of results (Honey 1979a).

The results stemming from the steps described above are often sets of "critical success factors' ranked according to perceived importance. Hence, using the example of characteristics of IS development methodologies, the results would be a list of grouped constructs describing characteristics that are reliable predictors of the effectiveness of IS methodologies. It is possible not only to identify those most closely associated with the effective methodologies but also the extent to which the experts who were participants in the research agree in this ranking.

\subsection{History}

The primary use of RepGrid is to investigate or reveal attitudes and beliefs (Honey 1979d: 452), concepts, assumptions (Honey 1979b: 358), perceptions (Honey 1979c: 407), and selfinsight or reflection (Honey 1979a: 358), that is, understanding and cognition (Tan and Hunter 2002). These personal views, as was explained in Section 3.1, are known as constructs. The technique was developed by Kelly in 1955 as part of the Theory of Personal Constructs described in 'The psychology of personal constructs' (Kelly 1955). He based his work on a position which he called 'constructive alternativism', with important basic premises (1) Humans progress and 'man-the-scientist' as an important way that the individual is able to predict and control his/(her) progress. This involves personal 'scientific' endeavour (constructing personal hypotheses and looking for empirical evidence to support these); (2) An external changing reality, admitting the 'reality' of people's thoughts as part of the external reality and recognising that that all elements of reality are ultimately functionally linked, with these links becoming apparent during the course of time; (3) Living organisms have the capacity of representing their environments and these representations are real; (4) Humans construct their own unique patterns fitted to reality in order to attempt to make sense of reality. Humans may add additional constructs or modify existing ones in order to improve their understanding of reality. Systems of constructs can be shared and communicated amongst humans. Although Kelly believes in an 'ultimate' construct of reality, he strongly emphasizes the 'locatedness in time', space and range of human systems of constructs; (5) Constructs are used by humans to predict aspects of reality and the outcome of the prediction compared to the actual course of events serve to validate a construct or leads to its modification or rejection.

Tan and Hunter (2002) refer to the RepGrid as a methodological extension of the Theory of Personal Constructs. The RepGrid technique attempts to uncover the personal theories (or personal constructs) of a number of knowledgeable participants on the topic chosen by the researcher, in order to allow a list of criteria for success to be complied, or some other framework, guidelines or insights to be produced. The simplest form of the technique was described in detail in Section 3.1 and will be referred to as the 'classic' form. However, it is important to note that the technique has evolved over time and Tan and Hunter (2002) describe a variety of ways in which it can be used. 


\subsection{Extensions to the RepGrid technique}

As noted above, the version of RepGrid described in Section 3.1 can be considered to be the original, or classic, version proposed by Kelly. Over time variations have evolved. RepGrids can be used with 'laddering' where the researcher probes the elements and constructs suggested by the interviewee by means of 'How' questions during a one-to-one interview. Laddering can assist in the hierarchical ordering of constructs (Stewart \& Stewart, 1990).

Hunter and Beck (2000) claim that this has resulted in, '... a structured, yet flexible, qualitative research interviewing technique, which decreases the potential for bias on the part of the researcher.' Occasionally either the elements or the constructs or both are prescribed by the researcher (Tan and Hunter 2002). Hence the researcher can play a more interventionist role than was described as the classic approach. As will be noted in the 'Case Study' (Section 4) and 'Research Method' (Section 5), the authors were even more directly involved during the process in which the RepGrid was used. Although triading was described in the description of the 'classic' use of RepGrid, it is not compulsory, all of the elements may be used while the constructs are being identified and scoring is done (Lee and Truex 2000; Tan and Hunter 2002).

Hence, further variation of the RepGrid technique, including the new variations explained later in this paper, are simply part of the evolution of the technique described in this section.

\subsection{Reasons for using the RepGrid technique}

RepGrid is one of many tools used to collect data and to assist in analyzing them, others being the Delphi technique and Focus Groups (see section 3.7 for a brief comparison). RepGrid is considered a methodological tool or instrument rather than a research method and can be compared with other data collection techniques such as questionnaires, observation or interviews. Some authors refer to it as an interview technique (Whyte and Blytheway 1996; Lee and Truex 2000). It is unusual in that the research subjects, rather than the researcher, identify the aspects of the topic (the constructs) that they think are important. Hence, it elicits value judgments since the constructs are explicitly formulated as identifying 'good' and 'bad' characteristics, or characteristics that explain success or failure. One major advantage of using RepGrid that is often emphasized is that it allows for independent, unbiased, 'uncontaminated' data implying that the researcher does not influence the results (Whyte and Blytheway 1996; Honey 1979b).

'A particular strength of the repertory grid technique is that it allows the elicitation of perceptions without researcher interference or bias.' (Whyte and Blytheway 1996)

RepGrid is very often used for evaluation and to compare the different constructs or points of view offered by the participants. This comparison of constructs allows reasons for differences to be probed and hence the technique is considered to have diagnostic qualities (Tan and Hunter 2002). Thus it has been useful within the IS context for finding out how role players structure and interpret information related to the introduction, development, and management of information systems. (Examples can be found in Hunter and Beck (2000) and Whyte and Bytheway (1996).)

RepGrids are considered to be an improvement on questionnaires, as the participants usually suggest both elements and constructs using their own words and reflecting their own experience. Hence, the participants' ideas and words are used to initiate evaluation in RepGrids instead of those of the researcher as is the case with questionnaires. This process contributes the 'uncontaminated data' referred to earlier, as the researcher is not suggesting issues of concern or asking leading questions. In addition, a richer set of data can be obtained than is the case in questionnaires with closed questions. It has a further advantage over questionnaires as the risk that different participants interpret questions differently is avoided. The data collection phase of the RepGrid technique is less resource hungry (takes less time and effort) than participant observation (Tan and Hunter 2002) and is also quicker to complete than interviews. It is, nevertheless considered by some authors to be a form of structured interview (Whyte and Blytheway 1996; Lee and Truex 2000). It differs significantly from a focus group because, although the participants often complete the RepGrids in the same place 
and at the same time, they do so as individuals and joint discussions do not take place. The constructs are personal and group constructs are only constructed later in the process.

\subsection{The RepGrid as an ideographic and a nomothetic technique}

Fransella et al. (2004) cite various examples of both idiographic and nomothetic use of RepGrid. These are reported as being in line with Kelly's own views that the one approach should not be to the exclusion of the other. As mentioned earlier, in the History section, during some analyses (for example, analysis of the joint content of several individually completed RepGrids (Tan and Hunter 2002)), the researcher needs to group constructs into attributes. A deliberate attempt is usually made to reduce research bias by using more than one expert to confirm the groupings (Whyte and Blytheway 1996; Honey 1979c). Thus, this research approach might be considered to support a predominantly positivist epistemology with objectivity, in the sense of the researcher deliberately attempting to play the role of an independent observer, an important goal and rigor considered to be an important means of achieving this. However, the very fact that the data being used is predominantly based on the personal perspectives of the participants means that the technique cannot be considered to be positivist in the same way that laboratory experiments that use measurable data are. It is for this reason that Lee and Truex (2000) and Tan and Hunter (2002) note that there are examples in IS research where it has been used idiographically (where the researcher interprets the data and the subjective nature of such interpretation implies that different researchers may not reach the same conclusions (Burell \& Morgan, 1979)) and others where is has been used nomothetically (where analysis follows inductive and deductive processes closely and independent researchers can be expected to arrive at the same or very similar conclusions). Eden and Ackermann (1998) warn of the dangers of too much 'meaningless' generation of statistical data based on analysis of repertory grids. Marsden and Littler (2000) point out that personal construct psychology derives from the interpretive paradigm and hence when using RepGrid as a technique supporting this underlying theory the same paradigm should be adhered to. Nevertheless, these same authors see as one of the main advantages of RepGrid its use of both quantitative and qualitative methods, which are not seen as being in conflict or contradictory, but can be integrated and be used to supplement one another. This view is supported by Trauth and Jessup (2000) when they point out the potential benefits in the complementary use of interpretive and positivist approaches to the research of socio-technical phenomena.

\subsection{Limitations of the RepGrid technique}

Despite the extensions described earlier, the RepGrid technique is well-defined. It is best suited to research where the participants have extensive practical experience since the requirements concerning elements are fundamental and can be difficult to satisfy. (The participant is expected to be able to identify a number of specific examples to use as elements and must be able to compare them.) The proposed elements need to be concrete, practical examples rather than more abstract entities. The elements used by the different participants are usually different and although this means that the final results are more generalizable it introduces a further degree of complexity into the model. The concrete nature of the elements, together with the need for a set number of examples can be a restriction to the use of this technique.

Furthermore, the constructs are quite clearly intended to be personal and not developed during focus group discussions. Hence they are not probed or elaborated on. The fact that the researcher subsequently groups constructs is in a sense artificial as the participants are not given the opportunity to confirm that their personal constructs are similar. This grouping is intended to find out whether the independent evaluations and rankings of constructs coincide rather than to develop shared meaning. Validation of data obtained from the subjects - which is critical for interpretative research - can therefore be said to be lacking. In short, RepGrid has not up until now been used as a way to facilitate collaboration. Indeed it was never intended for this purpose. Nevertheless, this can be considered to be a restriction. 
These limitations are what prompted this study. As will be described in the Research Context, there was a need for a tool that not only assisted the individual researchers in reflecting in a structured way on their own constructs, there was also a need to jointly develop shared concepts. Furthermore, in this study the authors were not studying a number of directly comparable cases (or elements) but instead were exploring abstract points of view (at the element level).

\subsection{A comparison of RepGrid with Nominal Group Technique, Delphi and Causal Mapping}

Other methods used for collaborative analytic purposes are Delphi (Dalkey and Helmer, 1963), nominal group technique (Van de Ven and Delbecq, 1974) and causal mapping (Ackermann and Eden, 2005). This section briefly discusses RepGrid within the context of these other methods and techniques.

The Delphi method (which has its roots in the military context of the cold war) (Dalkey and Helmer 1963) may be considered to be a consensus-seeking tool amongst experts in predicting an aspect of a complex situation. It presumes (similar to RepGrid) a focused problem, and then allow the experts whose opinions are being sought to estimate solutions to the problem through a series of questionnaires or interviews and controlled feedback. The intention is to get convergence of expert opinion without conflict between the experts. The convergence is based on the systematic elimination of any misconceptions that the experts may have regarding underlying assumptions that influence their judgment of the situation. Obviously the implicit linkage between underlying assumptions and expert opinion on the issue at hand influences the extent to which correction of misconceptions and agreement on underlying assumptions would influence the convergence of expert opinion. An important part of Delphi is that the experts are deliberately kept apart.

The nominal group technique (NGT) (Van de Ven and Delbecq, op. cit.) was developed in the context of the socio-psychological analysis of various real life situations such as conferences, citizen involvement in social planning, etc, It provides a structure that facilitates decision making in groups and allows the voices of individuals in the group to be heard and a group decision to be reached through voting on individual contributions.

Cognitive mapping (Ackermann \& Eden, 2005) derives from the contexts of political science and strategic management. Its focus is more on the individual than on group context (Ackermann \& Eden op. cit.). It facilitates a multi-perspective understanding of cause and effect in complex situations. Its focus therefore is on complex socio-physical systems and determining the shared and non-shared beliefs of actors involved in the situation (Laukkanen, 1998).

In comparing RepGrid to these other techniques, some important similarities and distinctions emerge; (1) All methods have structured methods and approaches; (2) Whereas NGT and Delphi are consensus seeking this requirement is not strong in causal mapping and RepGrid, which both allow for divergence of individual viewpoints; (4) Causal mapping and RepGrid share a focus on sense-making in role orientation of participants (3) NGT, Causal mapping and RepGrid all allow for nomothetic and idiographic approaches, while Delphi is nomothetic; (6) All the techniques are either independence or non-conformance tolerant.

\section{The Case Study}

In this section limited background is provided on the case study which led the researchers to extend the RepGrid to the RefGrid.

The Siyabuswa Educational Improvement and Development Trust (SEIDET) is a rural community-based project, which has been successfully sustained for more than twelve years. It was born out of a need identified by a rural community in South Africa for more black learners to pass Science and Mathematics up to matriculation level. Under the leadership of a community member, the initiative immediately generated significant interest and support in 
the community. As a result, it has since expanded to include various programmes offered at three centers.

An interesting aspect of SEIDET is the collaborative nature of the activities undertaken. One of the most significant has been the collaboration between SEIDET and the Department of Informatics at the University of Pretoria, which has benefited both parties significantly. From an academic perspective, the culture of trust that exists between these two entities has allowed researchers to do valuable research on the unique context and processes of SEIDET. Reports on this research have been published in various academic journals and proceedings of conferences (Conradie 1998; De Kock 2000; Phahlamohlaka and Friend 2004; Phahlamohlaka and Lotriet 2002a; Phahlamohlaka and Lotriet 2002b; Scheepers and de Villiers 1999; Siebeling 2004).

A decision was made during their 2004 Annual General Meeting that SEIDET has matured to a stage where it is ready to embark on a profit-making business of some sort and hence to play a role in programmes aimed at black economic empowerment and job creation. In addition, it was noted that funds needed to be generated that could be used to maintain the existing infrastructure and allow further growth. Since no one was sure how this could be done, it was decided that the Executive Committee (ExCo) be given two months to develop a proposal to be presented to the Board before the end of 2004. ExCo approached one of the authors for assistance. As a result four members of the Informatics Department identified a research opportunity and agreed to facilitate a workshop during which the ten members of ExCo would explore business opportunities. From a research perspective, both the nature of the occasion and the facilitation process received attention, whilst the researchers at the same time assisted ExCo to achieve their objectives.

Over the years, researchers in the Department of Informatics have facilitated several interventions at SEIDET and various facilitation techniques have been used with varying degrees of success (Phahlamohlaka and Friend 2004). These interventions have all been intended to enhance community-based development. The authors realized from the outset that this intervention (that is, the 'business opportunities' workshop) was distinctly different from previous ones, as the objectives have changed to include both altruistic and explicitly commercial aspects. Not only did this mean that special care had be taken to protect the original cause and nature of the organization, but that a different approach and techniques for the facilitation process was required. What went into the planning for the workshop has been reported in a separate paper (Alexander et al. 2005). This workshop was thus the stimulus for the collaboration for which the RepGrid was used but this paper is not intended to discuss the workshop process itself. Hence the design of the workshop is not of direct interest here.

After the workshop the four researchers identified the need for a structured method to evaluate the success of the action phase of the project (the workshop). During the evaluation, the use of the RepGrid was extended and conceptualised as the RefGrid method. As this paper is not about how successful the workshop was, but rather about the use of the RepGrid by the researchers as a collective and individual reflection technique, the workshop is, therefore, of interest only in that it was the topic which the researchers wanted to reflect upon.

\section{Research Method}

The authors' conceptualisation of the Reflective Grid technique could be described as a small Action Research project within the bigger Action Research project referred to in the previous section ('the case study'). In terms of the Susman and Evered (1978) AR phases, the conceptualisation of the RefGrid happened as follows:

\subsection{Diagnosis}

Researchers realised the need for a structured way to jointly evaluate activities as part of the $\mathrm{AR}$ for the project. 


\subsection{Action Planning}

On the basis of previous knowledge of the Repertory Grid technique an initial 'evaluation' was planned using a new version of this technique.

\subsection{Action Taking}

The research team members used the devised method to evaluate the research project.

\subsection{Evaluating}

The researchers critically evaluated their use of the revised RepGrid method within the context of their own research.

\subsection{Specifying learning}

The researchers formally articulated the processes, structures and deviations from the original RepGrid technique and documented this as the RefGrid concept.

\subsection{Discussion of the research approach}

In the research collaboration reported here, a fundamentally Interpretivist research approach was adopted together with the revised RepGrid technique. The goal was to reach a shared understanding of the individual assessments of the value of the workshop as indicated by the elements in Table 1.

The decision to use a version of RepGrid for reflection was made before the workshop. Thus there was an intentional separation between the SWOT analysis carried out during the workshop (considered to be the 'action stage') and the subsequent evaluation of the workshop process as part of the 'reflection stage'. RepGrid was chosen as the method allows individual researchers to record their personal perceptions, attitudes et cetera in a uniform and, importantly, in a structured way. However, from the start it was intended to be used as a tool for collaboration between the researchers. The researchers did not want to use it to assess the validity or feasibility of the decisions taken by the members of SEIDET either at, or after the workshop. Instead they wanted to examine their individual assumptions, perceptions and assessments of the workshop process and to use this input to share understanding. This is in line with the uses of RepGrid given in the literature outlined above. However, as the perceptions of only four people (the researchers) were being examined, this was not an appropriate case for statistical analysis as is typical in 'classic' RepGrid research. This highlights the difference between the research being reported here and other contexts where an independent consultant administers a RepGrid session as an uninvolved observer and analyses it objectively.

A very important point is that abstract elements involving characteristics of the workshop process were being evaluated by the individual researchers rather than concrete examples as can be seen from Table 1. RepGrid was then used to probe and compare these individual perceptions and different interpretations in order to reach a joint understanding rather than as a means of constructing and ranking lists of criteria for good behavioural qualities or best practice as is classically the case.

The participant researchers were engaged in an authentic research event, playing their normal professional roles but hoping to gain additional insights that would inform the ways in which they carried out these activities in research teams in future. Hence the research setting can be considered to be rather more valid than that where graduate students are required to work on tasks.

The Process section in the "Use of the RefGrid by the research team" will briefly describe how the group used the technique. The next section will explain in more detail how this use of the technique differs from the 'classic' use. 


\section{Use of the RefGrid by the research team}

\subsection{Process}

As can be seen in Figure 4, a four step process was used for the collaboration between the researchers. Step 1 involved 'Group Construct Elicitation' as explained by Tan and Hunter (2002) to identify elements, constructs and the bi-polar scales for the links between them. During a brainstorming meeting shortly after the workshop, the four group members jointly decided on the elements and constructs making up the RepGrid. A noted above, abstract characteristics rather than concrete examples were used as elements. (Refer to Table 1 - but note that not all of the elements identified are shown in the table). 'Laddering' was utilized as the group discussed each proposal critically before including it. The researchers did not include triading in devising the constructs. The reason for not using triads is embedded in the unusual use made in this case of the technique and is explained in the section below comparing the Reflection Grid (RefGrid) proposed in this paper with the 'classic' RepGrid technique.

The elements selected represented those aspects of the workshop that the researchers wanted to evaluate (that is, the objectives) while the constructs represented the measures that would be used in the evaluation of the elements. As noted above, the elements and constructs were all identified after the workshop. In future this should be done before the event in order to clarify what the criteria are and how these will be assessed and so as to allow the researchers to pay attention to these aspects during the event. A 9-point scale was chosen for the same reasons used by Hunter and Beck in their research, namely, it provides for a midpoint and it allows a sufficiently fine granularity.

Over the next few weeks, group members, independently and in different places, assigned values to the cells which associate constructs with elements (Step 2, Figure 4). Hence the individuals evaluated each aspect of the workshop experience (that is, each element) in terms of the constructs. Once this was done, one of the researchers consolidated the information into a single grid to assist the comparative analysis (Step 3 Figure 4). A graphical representation of the consolidated data was prepared in order to allow easy analysis of the data obtained from step 2. The group then met again to study the graphical presentation, compare the values assigned to each cell by the individuals and to discuss the underlying reasons for differences in perceptions (Step 4, Figure 4). Hence all the requirements for collaboration noted by Beers et al (2006), namely externalization, internalization, verification and acceptance or rejection, were satisfied.

This discussion highlighted differences in the individuals' understanding of the elements and constructs and made them reconsider their individual interpretations (a double hermeneutic process occurred (Giddens 1984: 284)). It made the team aware that the assumptions that individual members had made regarding the workshop, and the belief that we had already achieved substantial shared meaning in terms of the jointly constructed elements and constructs, were not well founded.

The value of the tool (the amended RepGrid, subsequently renamed Reflection Grid) in terms of the evaluation of the workshop process was that it facilitated openness and learning by ensuring that participants were consciously reflective. In the context of this study, the learning process included an increased awareness of how difficult it is to reach a persistent (relatively lasting), common understanding of the criteria being used in evaluation. A second impact was the resulting deeper, more considered discussion of the value of this particular workshop.

\subsection{Differences: Reflection Grid versus Repertory Grid}

The name of the grid technique used in the research workshop described above has been changed from Repertory Grid to Reflection Grid in order to acknowledge the differences in use and also to highlight our specific goal of encouraging collaboration by emphasizing joint reflection as well as the individual reflection implied by writing down personal constructs. 
The sections that follow will point out the differences in detail and will do so by looking at each of the steps identified in Figure 4 (The Reference Grid Development Process) in turn.

\subsubsection{Step 1: Selection of elements and constructs}

RepGrid elements have a single domain and are concrete examples of instances within that domain. The performance or skills of specific, known individuals from the domain, such as specific people, are evaluated using the constructs.

The elements selected in the case being described here do not, strictly speaking, comply with these requirements for RepGrid elements even though they too are ' $\ldots$ the objects of the research participant's interpretations' (Tan and Hunter, 2002). The elements used (Table 1) are different aspects of a single event, namely, the workshop. An appropriate, overall element domain name might be 'Workshop aspect' but this seems to fail the requirements of preciseness and homogeneity. Most particularly, these elements cannot be directly compared in the same way that one can compare the effectiveness of two systems analysts. Nor are there element instances which can be described as having good, medium or poor skills or aspects. In addition, more than the usual numbers of elements were identified, although a greater number is recognized as enriching the analysis.

The researchers did not use the triading technique in identifying personal constructs as this can only be done when the elements can be compared directly. Instead, the selection of group constructs was in the form of a discussion (see Table 2). (Subsequently this was found to have resulted in individuals forgetting the original meaning of the constructs, or possibly never having reached a common understanding of them.)

\subsubsection{Step 2: Data values}

This phase followed the usual procedure except that the participants worked at different times and places. Since the elements were not homogeneous, not all the constructs could be applied to all the elements and, as a result, the process was cognitively different from the usual RepGrid process and it proved to be challenging to assign values. The lapse in time between jointly deciding on elements and constructs and assigning data values, together with the implied need for everyone to have a common understanding of the intended meanings of these concepts, added to the uncertainty. However, the individual's control over the amount of time spent on the process did allow him or her to examine the concepts carefully and to explore his or her understanding of the concepts. The individual scores, although numeric, represented subjective, value judgements and fit well with ideographic or qualitative research although they might be mistaken for measures and hence appear to be quantitative.

\subsubsection{Step 3: Reformatting the grid}

This step did not require any interpretation or any clustering of constructs as the four participants had jointly decided on constructs earlier. Hence everyone used the same constructs. Once the completed grids were obtained from the researchers, one member of the team typed the four corresponding, numeric data values from the individual RepGrids into adjacent cells of a spreadsheet with the values color coded in order to identify which person provided that specific score. Graphic representations (multiple line graphs) per construct were produced in order to highlight agreement, trends and divergent opinions.

\subsubsection{Step 4: Analysis}

Joint inspection of the graphs resulted in a rich and interesting discussion that highlighted significant differences in understanding despite the fact that the elements and constructs had been jointly devised. The analysis was different from that used in classis RepGrid analysis as it was not necessary to compare and group constructs (everyone was using the same set). Instead the emphasis was on comparing the cell values presented by the different participants. The data from one of the researchers is provided in Table 1. This researcher felt that there was a very high degree of relevance (one of the elements) in discussions during the workshop in terms of both short term and long term collaboration (two constructs) and hence assigned of scores 2 and 1. However this researcher thought that the workshop discussions demonstrated very little critical thinking - the last element in the second set (scores varying from 5 to 6 for 
all constructs). When the scores of two colleagues (Researchers A and B) were compared it was clear that the one was far more likely to give scores above 6 than the other (that is, more negative scoring). This discrepancy was probed effectively in discussion and this revealed more than a statistical analysis would. Thus the individual value judgments indicated by the scores can be compared and differences in interpretation and understanding be highlighted. The technique is ideographic but goes beyond this nomothetic/ideographic dimension and the related objective/subjective ontology. It is neither objective nor subjective but intersubjective as it is used as a communication tool.

\section{Conclusion}

Table 3 summarizes the differences between the RepGrid and the RefGrid.

The Reflection grid is a unique adaptation of RepGrid which provides a method that collaborating researchers can use reasonably well to share ideas. Individual, subjective perceptions are taken into account, but in addition these can be explored and shared, thereby providing a way of validating qualitative research data. Discussion of misunderstood or different interpretations in terms of what was initially believed to be the same construct is essential in collaboration. This new perspective on how to use an existing tool supports collaborative research very effectively and can be used among either practitioners or researchers. It allows for shared criteria (Figure 4, Step 1), individual input (Figure 4, Step 2), systematic organization (involving all of the steps in Figure 4 but particularly Step 3) and combines further development of shared understanding (Figure 4, Step 4). Briggs, De Vreede and Nunamaker (2003) have identified five basic patterns of thinking that are required to move through a reasoning process, namely, Diverge, Converge, Organize, Evaluate, and Build Consensus. Convergence takes place in step 1, Divergence in step 2, Organizing particularly in Step 3 and both Evaluate and Build Consensus in Step 4. Hence this research method provides a form of group support system although not one in which technology plays a significant role.

The RepGrid technique is evolving and, as pointed out earlier, numerous versions are described in the literature. It is also clear from literature that the strength of the RepGrid in comparison to other techniques lies in its focus on individual constructs (i.e. the ability to elicit individual constructs from groups of experts with regard to the chosen research topic) which allows for inter-subjective or shared sense-making, within an idiographic context. The adaptations made to the technique which are described in this paper, can be considered to be a further evolution, made in order to accommodate a particular context and research objectives but suitable for more general use. On this particular occasion it was used to explore, in a highly structured way, the individual researchers' perceptions, assumptions and assessments of a workshop session. It proved very useful as a group support or collaboration tool. The application could be applied equally successfully to many other scenarios.

Since the authors departed quite fundamentally from the original RepGrid this adapted version has been referred to as a RefGrid rather than a RepGrid. The use of this new version of the technique emphasizes the reflective and interpretive processes necessary for understanding and making explicit personal, subjective meanings. This is necessary in collaboration in order to share and jointly form new, inter-subjective meaning, yet maintaining the original structure of the RepGrid. This supports important properties of effective teams (Eden \& Ackermann, 2001), namely, multiple interpretations of 'the same problem label' based on the different perceptions of the team members, relationship building (through the team exploring each others' interpretations of the constructs) and the fostering of freedom of expression and equality amongst team members (in terms of the validity of ideas expressed).

The fact that the researchers were both the organizers of the workshop and the users of the RefGrid is an essential aspect of this research. The implications are that the RefGrid is used where the researchers and research subjects are the same group (self reflection) whereas RepGrid expects the researchers to be objective and independent from the participants. 
As in any research, the work being reported on has some significant limitations. It should be noted that this paper is not intended to be a full discussion of the pro's and cons of the different approaches and adaptations of Repertory Grids. Such a discussion would indeed be valuable but is beyond the scope of a more focused journal article. It has therefore been identified as future work.

Further limitations include the fact that only one application of RefGrid is reported. Furthermore, there was no independent and hence monitoring researcher in this case. Hence, the introspective and inter-subjective nature of the collaboration, which was intensified by have the researchers both run the workshops and participate in the subsequent interpretation, was not 'balanced' by having an external party to advise, control, monitor or report on the process from an independent perspective. For example, there was no regulation during the element seeking phase and this resulted in a high number of elements. An independent researcher might have grouped these or been more critical. The technique does not exclude such a possibility.

The number of participants is lower than would be usual in research where RepGrid is used. This is not a limitation as four is a good number for a research team who need to collaborate. Nevertheless, future applications with larger numbers of collaborators would strengthen the claim to usefulness as collaboration becomes more difficult when the size of the team increases.

The RefGrid can be used by researchers and practitioners alike. For researchers, it provides a robust research method for use in qualitative research as described in this paper. A proposed use is especially where the qualitative research requires evaluation (e.g. during reflective phases of Action Research) and where this evaluation needs to happen collaboratively. To practitioners, it provides an easy-to-use, structured method to evaluate perceptions, assumptions and assessments. A RefGrid can be done on paper and be used by managers to encourage dialogue about particular concepts.

Future research will address the limitations identified and also extend the idea by focusing on the use of both the RepGrid and the Reflection Grid as Group Support Systems. The intention is to investigate in particular how technology can be used to support these processes while retaining the complementary ideographic and nomothetic aspects of the techniques. As noted above, a similar exercise with a moderator present would be valuable and this can be linked with the earlier suggestion regarding the use of technology. The moderator might be in the form of GSS technology or an independent researcher who would regulate only the process and not the content of the discussion.

Whereas much of the debate regarding the use of RepGrid in IS research has focused on whether RepGrid is nomothetic or ideographic or both, RefGrid as a collaboration tool has progressed beyond either a purely subjective or an objective approach and needs to emphasize interaction and hence an inter-subjective view. It is a tool that can be used by the individual to record and subsequently examine personal assumptions, beliefs and perceptions. At this level it is clearly ideographic as it concentrates on the subjective. However once these constructs are made explicit they can be shared, compared with the constructs of other participants and differences can be explored. An inter-subjective methodology that supports a socially constructed worldview is proposed in place of either a nomothetic or ideographic methodology.

\section{References}

Ackermann F, Eden C (2005) Using causal mapping with Group Support Systems to elicit an understanding of failure in complex projects: some implications for organizational research. Group Decision and Negotiation 14:355-376

Alexander PM (2002) Teamwork, time, trust and information. In: Kotze P, Venter L, Barrow J (eds) SAICSIT'2002 Enablement through Technology. ACM International Conference Proceedings Series (ACM Digital Library), 65-74

Alexander PM (2004) Implied information adds richness to 'lean' media. Communicare 23(1):197-219 
Alexander PM, Lotriet HH, Phahlamohlaka LJ, van Loggerenberg J (2005) Collaboration: Unearthing business opportunities for a rural community in South Africa. Paper presented at the IFIP 9.4 conference, May 2005, Abuja, Nigeria.

Baskerville R, Pries-Heje J (1999) Grounded action research: a method for understanding IT in practice. Accounting, Management and Information Technology: 1-23

Beers PJ, Boshuizen HPA, Kirschner PA, Gijselaers WH (2006) Common ground, complex problems and decision making. Group Decision and Negotiation 15:529 - 556

Bell RC, Vince J (2002) Which vary more in repertory grid data: constructs or elements? Journal of Constructivist Psychology 15:305-314

Briggs, RO, De Vreede, G-J, Nunamaker, JF (2003) Collaboration engineering with thinkLets to pursue sustained success with Group Support Systems. Journal of Management Information Systems 19(4):31-64

Burrell G, Morgan G (1979) Sociological Paradigms \& Organizational Analysis. Heinemann, London..

Conradie D P (1998) Using information and communication technologies (ICTs) for development at centers in rural communities: lessons learned. Communicare 17(1):97-116

Dalkey N, Helmer O (1963) An experimental application of the Delphi Method to the use of experts. Management Science (9)3:458-467

De Kock DM (2000) Innovative teacher education and interactive technology support. South African Journal of Higher Education 14(3):204-214

De Bono E (1992) Serious Creativity. Harper Collins publishers, London.

de Vreede G-J, Mgaya RJ, Quresh S (2003) Field experiences with collaboration technology: A comparative study in Tanzania and South Africa. Information Technology for Development 10.

Dix A, Ormerod T, Twidale M, Sas C, de Silva PAG, McKnight L (2006) Why bad ideas are a good idea. In: Proceedings of HCIEd2006 HCI Educators' workshop, March 2006, Limerick, Ireland

Eden C, Ackermann F (2001) Group decision and negotiation in strategy making. Group Decision and Negotiation 10(2):119-140

Eden C, Ackermann F (1998) Analysing and comparing idiographic causal maps In Eden C, Spender J C (eds) Managerial and organisational cognition. Sage Publications Ltd, London.

Finholt T (2001) Collaboratories, In B. Cronin (Ed.) Annual Review of Information Science and Technology. Washington, DC: American Society for Information Science and Technology:73 -108

Fransella F, Bell R, Bannister D (2004) A manual for Repertory Grid technique. John Wiley and Sons, Chichester.

Giddens A (1984) The constitution of society. University of California Press, Berkeley.

Harter S L, Erbes C R (2004) . Content analysis of the personal constructs of female sexual abuse survivors elicited through repertory grid technique. Journal of Constructivist Psychology 17:27-43

Honey P (1979a) The repertory grid in action. Industrial \& Commercial Training Nov79, 11(11):358358

Honey P (1979b) The repertory grid in action: How to use it as a pre/post test to validate courses. Industrial \& Commercial Training Nov79 11(11):359-369

Honey P (1979c) The repertory grid in action: How to use it as a self insight exercise. Industrial \& Commercial Training Nov79 11(11):407-414

Honey P (1979d)The repertory grid in action: How to use it to conduct an attitude survey. Industrial \& Commercial Training Nov79 11(11):452-459

Hunter MG, Beck JE (2000) Using repertory grids to conduct cross-cultural Information Systems research. Information Systems Research 11(1):93

Iversen JH, Mathiassen L, Nielsen PA (2004) Managing Risk in Software Process Improvement: An Action Research approach. Management Information Systems Quarterly 28(3): 395 - 433

Jarvenpaa SL, Leidner DE (1998) Communication and Trust in Global Virtual Teams. JCMC 3(4), June 1998.

Kelly GA (1955) The psychology of personal constructs. Volume one - a theory of personality. WW Norton \& Company, New York.

Laukkanen M (1998) Conducting causal mapping research: Opportunities and Challenges. In Eden C, Spender JC (eds) Managerial and organisational cognition. Sage Publications Ltd, London.

Lee J, Truex DP (2000) Exploring the impact of formal training in ISD methods on the cognitive structure of novice information systems developers. Info Systems J 10:347-367

Lindgren R, Henfridsson O, Schultze U (2004) Design Principles for Competence Management Systems: A Synthesis of an Action Research Study. Management Information Systems Quarterly 28(3): $435-472$

Marsden D, Littler D (2000) Repertory Grid technique: An interpretive research framework. European Journal of Marketing 34(7):816-83 
Mårtensson P, Lee AS (2004) Dialogical Action Research at Omega Corporation. Management Information Systems Quarterly 28(3): 507 - 536

Phahlamohlaka LJ, Friend J (2004) Community Planning for Rural Education in South Africa. European Journal of Operational Research (152):684-695

Phahlamohlaka LJ, Lotriet HH (2002a) An investigation into community development imperatives brought about by the recent establishment of a local area network and access to the Internet at a rural South African community education center. In: Proceedings of the Seventh International Working Conference of IFIP WG 9.4: Bangalore, India, 29-31 May, pp.462-476

Phahlamohlaka LJ, Lotriet HH (2002b) The impact of computer hardware theft on ICT introduction to South African rural communities: an interpretive assessment through Focus Groups and Morphological Analysis. In: Proceedings of the United Kingdom Systems Society Conference, York, United Kingdom, 07-10 July, pp. 283-292

Scheepers H, De Villiers C (1999) Teaching of a Computer Literacy Course: A case study using traditional and co-operative learning. In: Proceedings of the 7th European Conference on Information Systems (ECIS), Copenhagen, Denmark.

Siebeling T (2004) A novel approach to innovation processes in community driven projects: How an extended learning selection model explains the success of ABC, an educational community development project in rural South Africa. Unpublished M.Sc dissertation. Eindhoven University of Technology.

Stewart V, Stewart A (1990) Business applications of repertory grid. McGraw-Hill, United Kingdom.

Susman, G, Evered R (1978) An assessment of the scientific merits of action research. Administrative Science Quarterly 23(4): 582 - 603

Tan FB, Hunter MG (2002) The repertory grid technique: A method for the study of cognition in Information Systems. MISQ 26(1):39-57

Trauth, EM, Jessup, LM (2000) Understanding computer-mediated discussions: Positivist and Interpretive analyses of Group Support System Use. MISQ 24(1): 43 - 79.

Van de Ven AH, Delbecq A (1974) The effectiveness of Nominal, Delphi and Interacting Group Decision making processes. The Academy of Management Journal 17(4):605-621

Whyte G, Bytheway A (1996) Factors affecting information systems' success. International Journal of Service Industry Management 7(1):74-93 
Repertory Grid for collaboration \& reflection 1 of 8

\section{ATTACHMENTS: GRAPHIC ILLUSTRATIONS}

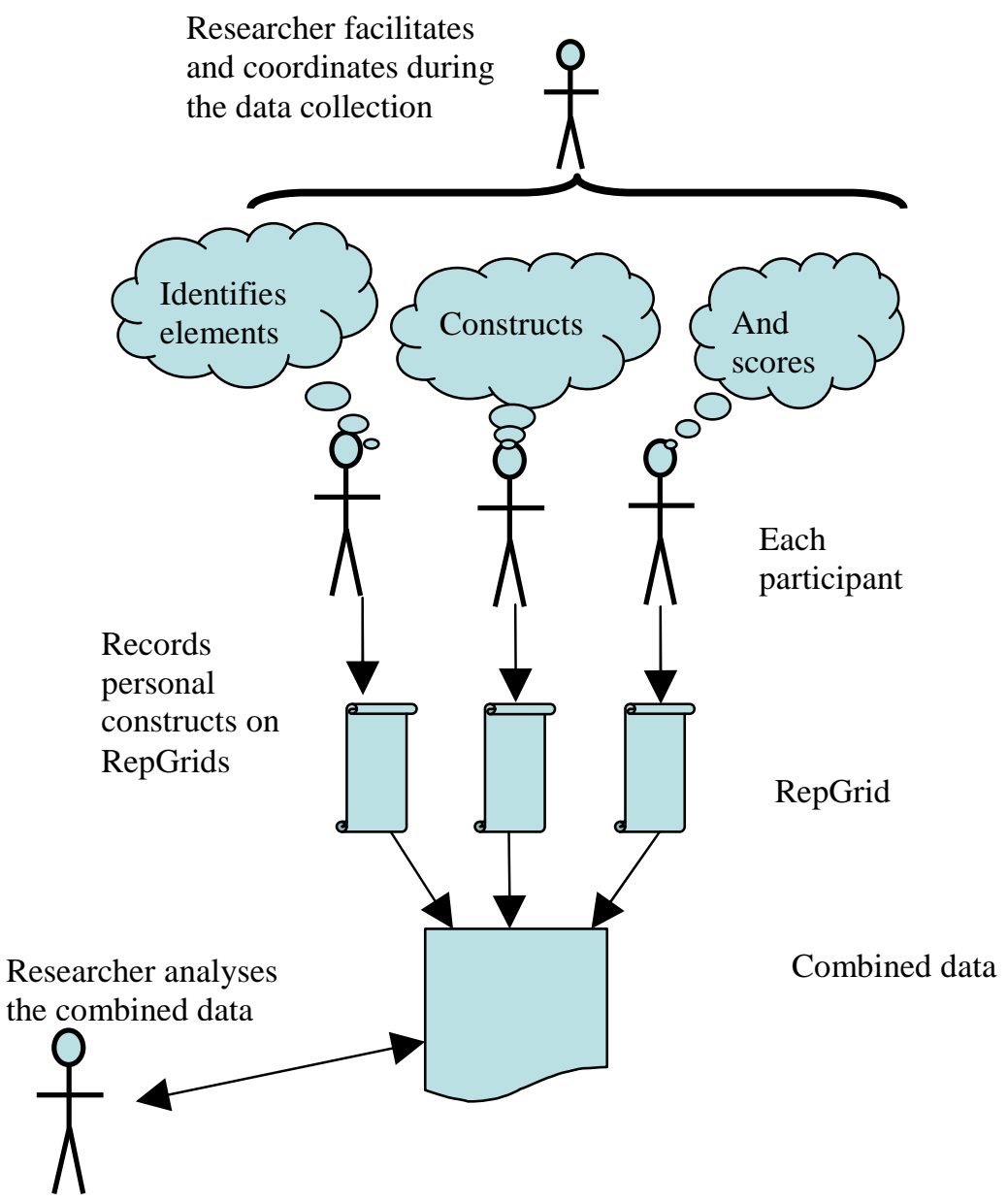

Figure 1: Role players 


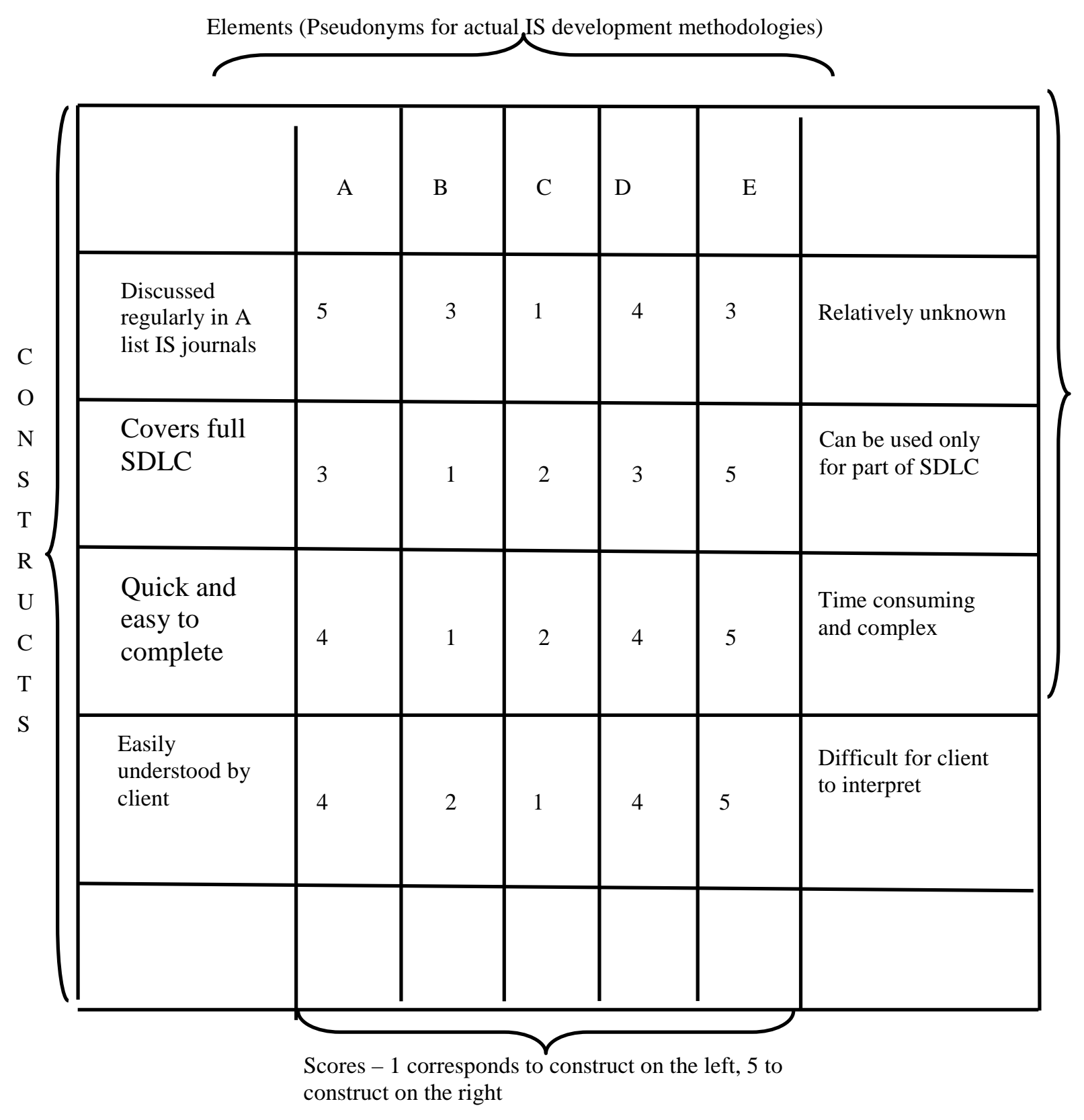

Figure 2: Example of personal constructs: Topic IS development methodologies 
Repertory Grid for collaboration \& reflection 3 of 8

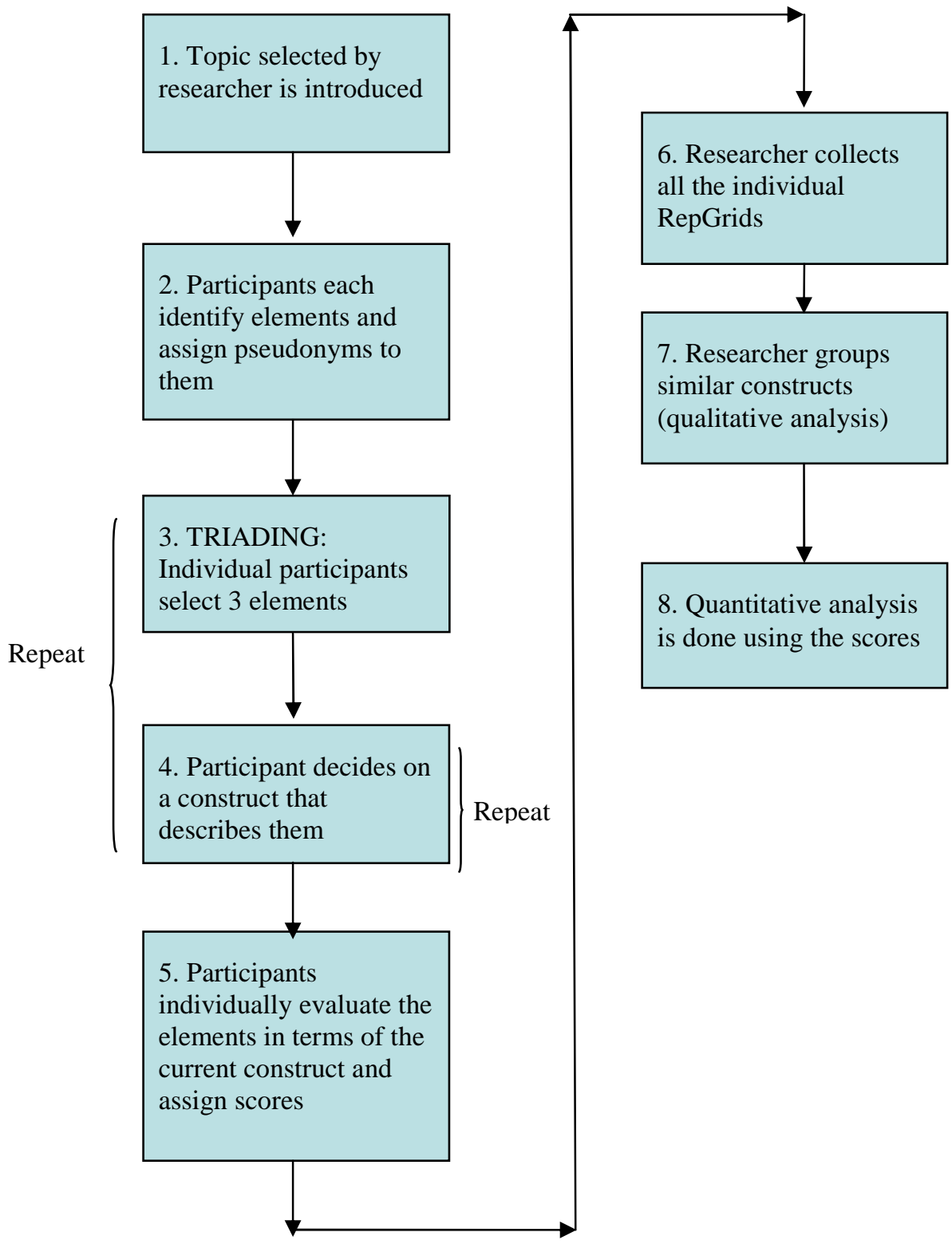

Figure 3: The RepGrid process 


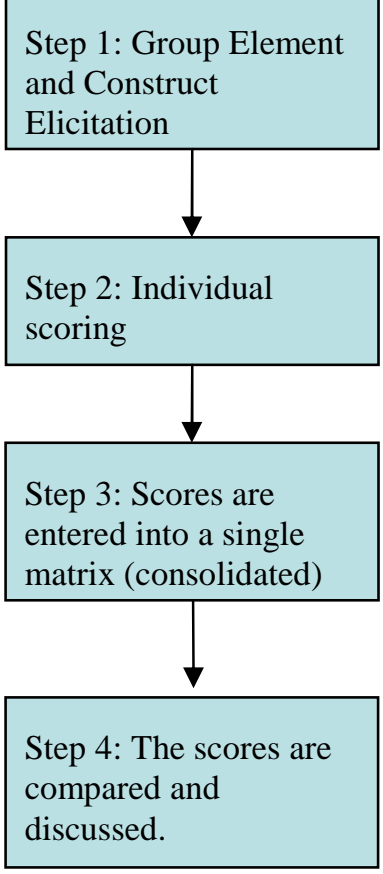

Figure 4: The Reference Grid Development Process 
Table 1. The Workshop aspects used as elements in our research Text Style

\begin{tabular}{|c|c|c|c|c|c|c|c|c|c|c|c|c|}
\hline & & \multicolumn{11}{|c|}{ Constructs } \\
\hline \multicolumn{2}{|l|}{ Elements } & $\begin{array}{l}\text { Creat- } \\
\text { iveness }\end{array}$ & $\begin{array}{l}\text { Sophisti } \\
\text {-cation }\end{array}$ & $\begin{array}{l}\text { Sponta- } \\
\text { neity }\end{array}$ & $\begin{array}{l}\text { Feasi- } \\
\text { bility }\end{array}$ & $\begin{array}{l}\text { Number } \\
\text { of ideas }\end{array}$ & $\begin{array}{l}\text { Expect- } \\
\text { ations }\end{array}$ & $\begin{array}{l}\text { Effect- } \\
\text { iveness }\end{array}$ & Efficiency & Scope & $\begin{array}{l}\text { Rele- } \\
\text { vance }\end{array}$ & Variety \\
\hline \multirow{2}{*}{$\begin{array}{l}\text { UP:SEIDET; UP:UP; } \\
\text { SEIDET: SEIDET } \\
\text { Collaboration on the day }\end{array}$} & $\begin{array}{l}\text { Researcher } \\
\text { A }\end{array}$ & 6 & 6 & 2 & 3 & 6 & 7 & 6 & 6 & 9 & 2 & 5 \\
\hline & $\begin{array}{l}\text { Researcher } \\
\text { B }\end{array}$ & 3 & 2 & 4 & 5 & 4 & 3 & 2 & 6 & 4 & 2 & 3 \\
\hline \multirow{2}{*}{$\begin{array}{l}\text { UP:SEIDET; UP:UP; } \\
\text { SEIDET: SEIDET } \\
\text { Collaboration longer term }\end{array}$} & $\begin{array}{l}\text { Researcher } \\
\text { A }\end{array}$ & 4 & 2 & 7 & 6 & 5 & 6 & 5 & 7 & 1 & 1 & 4 \\
\hline & $\begin{array}{l}\text { Researcher } \\
\text { B }\end{array}$ & 3 & 2 & 4 & 5 & 4 & 3 & 2 & 6 & 4 & 2 & 3 \\
\hline
\end{tabular}

\begin{tabular}{|c|c|c|c|c|c|c|c|c|c|c|c|c|}
\hline Elements & Enthusiasm & $\begin{array}{l}\text { Commit- } \\
\text { ment }\end{array}$ & Change & Quality & Openness & $\begin{array}{l}\text { Sensiti- } \\
\text { vity }\end{array}$ & $\begin{array}{l}\text { Demo- } \\
\text { cratic }\end{array}$ & Respect & \begin{tabular}{|l} 
Aware- \\
ness
\end{tabular} & $\begin{array}{l}\text { Informa- } \\
\text { tion }\end{array}$ & $\begin{array}{l}\text { Knowledg } \\
\text {-ibility }\end{array}$ & \begin{tabular}{|l} 
Being \\
Critical
\end{tabular} \\
\hline \multirow{2}{*}{$\begin{array}{l}\text { UP:SEIDET; UP:UP; } \\
\text { SEIDET:SEIDET } \\
\text { Collaboration on the } \\
\text { day }\end{array}$} & 6 & 3 & 5 & 5 & 5 & 3 & 3 & 3 & 3 & 7 & 6 & 6 \\
\hline & 2 & 2 & 3 & 3 & 4 & 2 & 2 & 2 & 2 & 2 & 3 & 6 \\
\hline \multirow{2}{*}{$\begin{array}{l}\text { UP:SEIDET; UP:UP; } \\
\text { SEIDET:SEIDET } \\
\text { Collaboration longer } \\
\text { term }\end{array}$} & 5 & 4 & 9 & 2 & 6 & 4 & 6 & 6 & 1 & 4 & 7 & 5 \\
\hline & 2 & 2 & 3 & 3 & 4 & 2 & 2 & 2 & 2 & 2 & 3 & 6 \\
\hline
\end{tabular}


Table 2. The Constructs and scales used to evaluate the Workshop aspects (elements)

\begin{tabular}{|c|c|c|}
\hline Construct & Scale & \\
\hline Creativeness: & 1: Very & 9: Not \\
\hline Sophistication & 1: Very & 9: Naive \\
\hline Spontaneity & 1: Very & 9: Not (Considered) \\
\hline Feasibility & 1: Highly & 9: Not \\
\hline Number & 1: Lots & 9: Few \\
\hline Expectations & 1: Met & 9: Not met \\
\hline Effectiveness & 1: Very & 9: Minimal \\
\hline Efficiency & 1: Very & 9: Minimal \\
\hline Scope & 1: Broad & 9: Narrow \\
\hline Relevance & 1: High & 9: Low \\
\hline Variety & 1: High & 9: Low \\
\hline Enthusiasm & 1: High & 9: Low \\
\hline Commitment & 1: High & 9: Low \\
\hline Change & 1: Radical & 9: Unchanged \\
\hline Quality & 1: High & 9: Low \\
\hline Openness & 1: Open & 9: Closed \\
\hline Sensitivity & 1: Very & 9: Not \\
\hline Democratic & 1: Egalitarian & 9: Autocratic \\
\hline Respect & 1: High & 9: Low \\
\hline Awareness & 1: High & 9: Low \\
\hline In-formation & 1: Formed & 9: Not formed \\
\hline Knowledgibility & 1: High & 9: Low \\
\hline Being Critical & 1: High & 9: Low \\
\hline
\end{tabular}


Table 3: A comparison of RepGrid and RefGrid

\begin{tabular}{|c|c|c|c|c|}
\hline & Characteristic & $\begin{array}{l}\text { RepGrid as used in IS } \\
\text { research }\end{array}$ & RefGrid & Notes \\
\hline 1 & $\begin{array}{l}\text { Research } \\
\text { subjects }\end{array}$ & Experts & Research team members & \\
\hline 2 & Focus on & $\begin{array}{l}\text { Understanding expert } \\
\text { subjects' views }\end{array}$ & $\begin{array}{l}\text { Understanding of } \\
\text { researchers' constructs and } \\
\text { elements }\end{array}$ & \\
\hline 3 & Epistomology & $\begin{array}{l}\text { Predominantly positivist } \\
\text { (with objectivity) }\end{array}$ & $\begin{array}{l}\text { Mainly interpretivist/ Anti- } \\
\text { positivist }\end{array}$ & \\
\hline 4 & Process & Structured & Structured & \\
\hline 5 & Choice of topic & $\begin{array}{l}\text { Researcher chooses } \\
\text { research topic and subjects } \\
\text { choose constructs and } \\
\text { elements }\end{array}$ & $\begin{array}{l}\text { Elements to be reflected } \\
\text { upon are chosen jointly by } \\
\text { researchers who are also } \\
\text { research subjects }\end{array}$ & \\
\hline 6 & Type of data & $\begin{array}{l}\text { Provides quantitative and } \\
\text { qualitative data }\end{array}$ & $\begin{array}{l}\text { Provides quantitative and } \\
\text { qualitative data }\end{array}$ & \\
\hline 7 & Purpose & $\begin{array}{l}\text { To reveal attitudes, beliefs, } \\
\text { concepts, assumptions and } \\
\text { perceptions of research } \\
\text { subjects, as experts in a } \\
\text { domain, in a structured way } \\
\text { in order to reveal } \\
\text { characteristics of the } \\
\text { research topic (often critical } \\
\text { success factors) }\end{array}$ & $\begin{array}{l}\text { To reveal attitudes and } \\
\text { beliefs, concepts, } \\
\text { assumptions perceptions } \\
\text { and self-insight or } \\
\text { reflection (understanding } \\
\text { and cognition) of research } \\
\text { team members about } \\
\text { elements in a structured } \\
\text { way in order to reach } \\
\text { shared meaning }\end{array}$ & $\begin{array}{l}\text { Honey 1979: 452; } \\
\text { Honey 1979: 358; } \\
\text { Honey 1979: 407; } \\
\text { Honey 1979: 358; } \\
\text { Tan and Hunter } \\
2002\end{array}$ \\
\hline 8 & Method/Tool & $\begin{array}{l}\text { Considered a } \\
\text { methodological tool rather } \\
\text { than research method }\end{array}$ & $\begin{array}{l}\text { Considered a } \\
\text { methodological tool rather } \\
\text { than research method }\end{array}$ & \\
\hline 9 & $\begin{array}{l}\text { Use of statistical } \\
\text { analysis }\end{array}$ & $\begin{array}{l}\text { Statistical techniques often } \\
\text { used for analysis }\end{array}$ & $\begin{array}{l}\text { Only elementary } \\
\text { descriptive statistical } \\
\text { techniques used for } \\
\text { analysis. }\end{array}$ & $\begin{array}{l}\text { Lee and Truex } \\
\text { 2000; Bell et al. } \\
\text { 2002; Harter et al. } \\
2003\end{array}$ \\
\hline 10 & $\begin{array}{l}\text { Role of } \\
\text { researcher }\end{array}$ & $\begin{array}{ll}- & \text { Researcher is a } \\
\text { facilitator } \\
\text { - }\end{array}$ & $\begin{array}{l}\text { Researcher is a } \\
\text { participant } \\
\text { Researchers' ideas and } \\
\text { words are used to } \\
\text { initiate evaluation } \\
\end{array}$ & \\
\hline 11 & $\begin{array}{l}\text { Diagnostic } \\
\text { abilities }\end{array}$ & Diagnostic & Diagnostic & $\begin{array}{l}\text { Tan \& Hunter } \\
2002\end{array}$ \\
\hline 12 & Methodology & $\begin{array}{l}\text { Ability to be used } \\
\text { idiographically (where } \\
\text { the researcher interprets } \\
\text { the data and the }\end{array}$ & Reflexive & $\begin{array}{l}\text { Lee and Truex } \\
\text { (2000); Tan and } \\
\text { Hunter (2002) }\end{array}$ \\
\hline
\end{tabular}




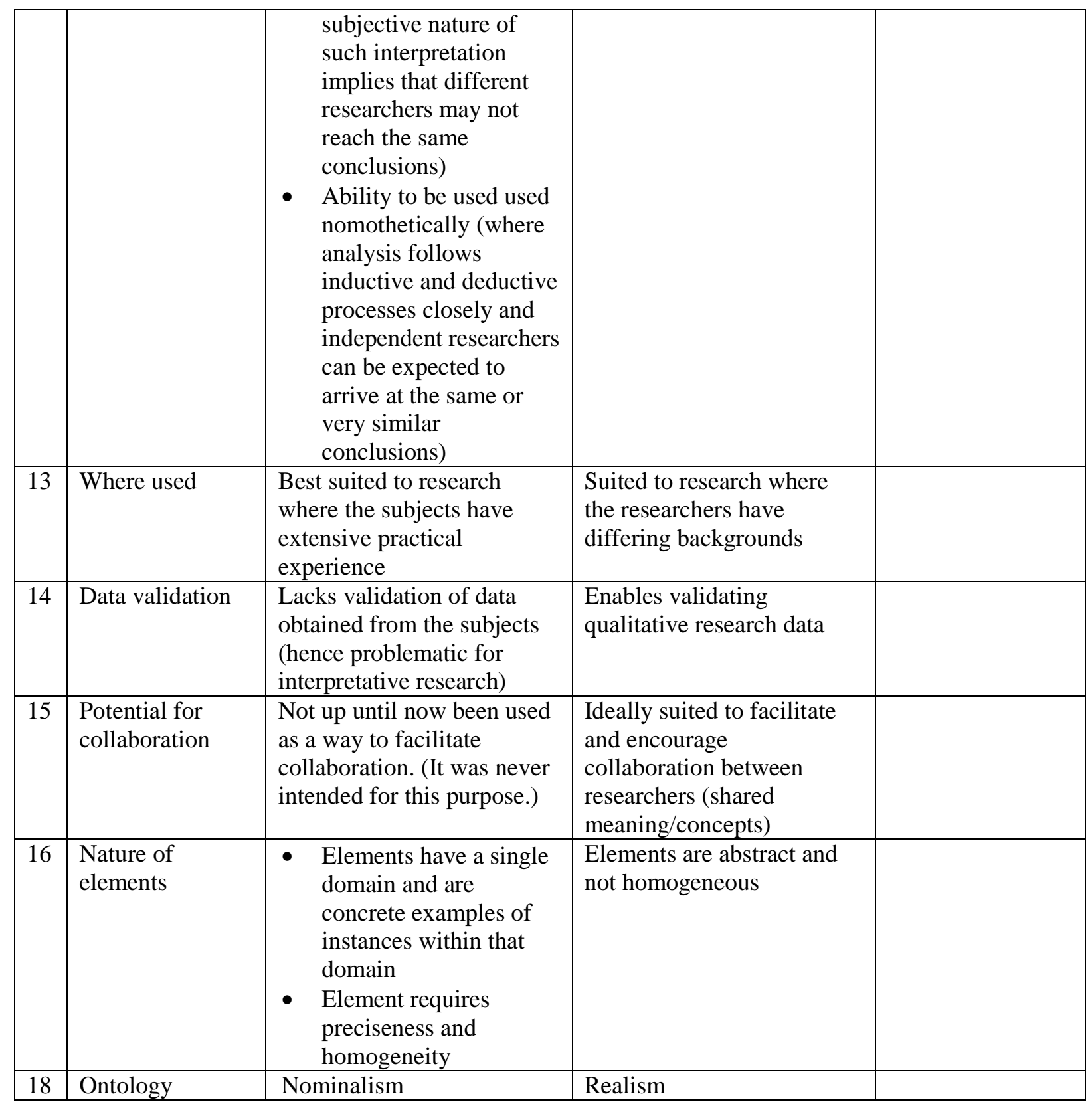

